\title{
SPEAK YOUR TRUTH: THE APPLICATION AND LIMITATIONS OF NARRATIVE THERAPY IN TREATMENT OF ANXIETY DISORDERS IN INDIAN WOMEN
}

\author{
Heiyya Kapoor \\ The Shri Ram School, Aravali \\ DOI: 10.46609/IJSSER.2020.v05i07.027 URL: https://doi.org/10.46609/IJSSER.2020.v05i07.027
}

\begin{abstract}
Indian women are disproportionately burdened by psychological illnesses including anxiety and depression disorders, which prevent them from emancipating themselves in a society that aligns themselves with patriarchal principles and values. This paper has determined that regressive social norms that deny women in India agency and mobility are responsible for a higher prevalence of anxiety disorders amongst Indian women as compared to their male counterparts. Narrative therapy is a type of psychotherapy that allows patients and therapists to co-author positive and empowering narratives that are based on their values and skills to counter negative stereotypes and discourse enforced upon patients by oppressive social hierarchies. This paper has found that narrative therapy has been effective in treating anxiety disorders, especially amongst individuals belonging to marginalized communities. Women in India face a plethora of barriers that prevent their access to mental healthcare. This paper has determined that there is an urgent need to implement narrative therapy in India, in combination with other therapeutic practices to develop Eclectic therapy models in an attempt to improve the lives of women suffering from anxiety disorders.
\end{abstract}

Keywords: Therapy, Anxiety, psychotherapy, Healthcare, Treatment

\section{INTRODUCTION}

Narrative therapy is a type of psychotherapy that depends on helping patients identify their values and the skills associated with them, the awareness of which enables them to develop a deeper understanding of the problem faced by them. The focus lies on helping individuals by helping them develop narratives about themselves based on an investigation of their historical and present perceptions, attitudes, and values (White \& Epston, 1990). It takes a social justice approach to therapeutic conversations, by challenging dominant social narratives that have a 


\section{International Journal of Social Science and Economic Research}

ISSN: $2455-8834$

Volume: 05, Issue: 07 "July 2020"

detrimental impact on individuals' lives and deconstructing them (Winslade \& Monk, 2000). They are replaced by empowering narratives that often challenge traditional social hierarchies. Narrative therapy is thus considered beneficial for members of communities that face oppression and exclusion in professional, educational, and public spaces. Narrative therapy bases itself on the work of Michel Foucault and seeks to establish the impact of social narratives around individuals and their communities on their mental and cognitive functioning (White \& Epston, 1990). It challenges the perspective deficit faced by many individuals who face structural discrimination throughout their lives without being aware of it.

Since its development in the 1970s and 1980s, it has gained popularity and traction across the world. However narrative therapy, along with many other forms of psychotherapy and counselling methods continues to be unexplored and underdeveloped in the Indian context (Mehta, 2019). Its usage is limited to the work done by non-governmental organizations and private mental health clinics in the metropolitan cities of India and continues to be inaccessible to the majority of the Indian population. It has been used to tackle a wide range of mental health issues including anxiety, personality disorders, depression, trauma, and abuse. Narrative Therapy is perceived positively by Indian psychologists because unlike cognitive and behavioral techniques, which reduce their patients to individuals who need rescuing, narrative therapy provides patients with perspective and information to understand their problems from their own unique lenses.

Anxiety is an emotion that all individuals experience through the course of their lives. It is considered to have been in the process of development and evolution because when it is experienced in moderation, it stimulates an anticipatory and adaptive response to challenging and stressful situations. However, in excess, it destabilizes an individual's cognitive and mental functioning. It is considered to be pathogenic when it arises without the presence of a challenge or stress or when it is disproportionately more than the challenge of stress in terms of duration or severity, or when it presents challenges to social, emotional, or psychological functioning (Trivedi \& Gupta, 2010). According to the Diagnostic and Statistical Manual, anxiety disorders include a wide range of mental health issues ranging from panic disorder, social phobia, generalized anxiety disorder, post-traumatic stress disorder, and obsessive-compulsive disorder. Research into the prevalence of anxiety disorders in India is nascent and underdeveloped. This is because of the stigma around mental health in Indian society, which contributes to the low-rate of diagnosis and treatment, and to the ignorance of public health officials. Research conducted in 2017 suggests that mental illnesses, including anxiety disorders, are more prevalent amongst Indian women as compared to men (Sagar, et. al., 2017). This can be attributed to both biological and social factors (Kohli, 2019). The novel and groundbreaking research suggest that $3.9 \%$ of Indian women suffer from anxiety disorders, and the corresponding figure for men is $3.3 \%$ 


\section{International Journal of Social Science and Economic Research}

ISSN: $2455-8834$

Volume: 05, Issue: 07 "July 2020"

(Sagar, et. al., 2017). It should be noted that underdiagnosis contributes to the deflation of actual cases of mental health issues in India, especially amongst women. Despite the high occurrence of anxiety amongst women, fewer women seek treatment for it as compared to men (Kohli, 2019).

Eclectic therapy includes therapeutic approaches that incorporate a wide range of therapeutic principles and philosophies in an attempt to create ideal treatment programs that meet the context-specific needs of the patient. Personalization and contextualization of therapy yield better outcomes, and a one-size-fits approach rarely works for therapeutic practices. Therefore therapists and clinical psychologists attempt to create a routine that involves principles from different approaches that best suits the patients' needs (Norcross, 2007). Narrative therapy cannot individually tackle serious cases of mental disorders which is why it is combined with a number of approaches cognitive-behavior therapy, counselling, mindfulness-based cognitive therapy, and so on to create patient-specific eclectic treatment approaches (Melchert, 2011).

\section{BACKGROUND}

Narrative therapy focuses on helping people in creating positive narratives and stories about themselves. The 're-authoring' of narrative allows people to identify and engage with their skills and values, which can go a long way in improving the quality of lives led by them. Therapists attempt to use narration to dispel negative stereotypes that their patients have about themselves, and replace them with positive values in their psyche (Brown \& Augusta-Scott, 2007). This process of co-authoring narratives involves intensive engagement between therapists and patients. The narrative process allows individuals to capitalize on values and skills that they think are important for them. Narrative therapy is interlinked with identity. Instead of focusing on the biologically determined 'true nature' of individuals, it perceives identity as a social construct, which is determined by social narratives and individual choices (White, 2007).

Unlike traditional talk therapy, narrative therapy externalizes the therapeutic process by separating an individual's identity from the problems faced by them and tracing a link between the two. It also allows an individual to examine their skills and values from an external lens, and hence construct positive narratives about themselves (White \& Epston, 1990). The narrative approach also adopts a collaborative therapeutic instead of an imposing once since positive narratives are co-authored. Instead of the therapist exclusively constructing narratives, patients are allowed to construct their 'preferred identity'. Providing implicit instead of explicit cues and solutions to problems enhances the commitment rates of patients and the efficacy of the therapeutic process (White, 2007). Social oppression, which often manifests itself in the form of mental illnesses is often internalized by individuals. Patients, therefore, start blaming themselves for their problems and mental health issues instead of attributing blame to oppressive and exclusionary structures. By facilitating the creation of positive narratives, individuals are able to 


\section{International Journal of Social Science and Economic Research}

ISSN: $2455-8834$

Volume: 05, Issue: 07 "July 2020"

escape negative self-perceptions (White, 2007). The separation of problems from personal identity also aids in the process of objective evaluation. The non-hierarchical nature of narrative therapy, which promotes an individual's sense of worth separates narrative therapy from traditional forms of talk therapy (Mehta, 2019).

Anxiety disorders, especially social anxiety often stem from negative stereotypes that surround individuals, which diminish their sense of self and contribute to higher and unwarranted levels of panic and stress. Individuals develop anxiety when they feel that those around them view them negatively, or associate inferior traits with them. The detrimental effect on an individual's selfesteem begins from the early stages of development and continues to affect people throughout their lives. Narrative therapy attempts to dispel these negative narratives and hence has become popular amongst psychologists as an effective tool against anxiety disorders. Research that sought to investigate the role of narrative therapy in reducing social anxiety amongst teenagers in Shiraz concluded that narrative therapy contributes to improved social interactions of those diagnosed with anxiety disorders (Ravan \& Esfandeyari, 2016). Similarly, research conducted by Ghavani, et. al. which sought to examine the effectiveness of narrative therapy on girl students concluded that it was effective in decreasing the level of social anxiety and increasing levels of self-esteem amongst the experimental group (Ghavami, et. al., 2014). Evidence also suggests that group narrative therapy reduces social phobia amongst children and improves their self-esteem and feelings of fear (Looyeh, et. al., 2014). Research conducted in African refugee settlements concluded narrative therapy to be effective in the treatment of post-traumatic stress disorder amongst children and adolescents (Kangaslampi, et. al., 2017)

\section{DISCUSSION}

Narrative therapy has faced criticism due to its theoretical and methodological inconsistencies since its conception (Fish, 1993). It bases itself on postmodern social thought promulgated by the likes of Foucault and Derrida. Hence it suffers from criticism similar to the criticisms of postmodern thought- that there is no absolute truth and only socially constructed narratives. Narrative therapists, hence, only privilege their client's concerns over and above "dominant cultural narratives (Minuchin, 1998). Moreover, by allowing patients to self-author their narratives, therapists might lead their clients to use those narratives to escape reality and not transform it positively. The detachment from conventional forms of psychotherapy and its focus on postmodern thought and literature also presents challenges in combining it with other forms of therapy to develop unique and personalized Eclectic therapy programs for patients. Lastly, narrative therapy is criticized for the lack of clinical and empirical studies that validate and verify its claims (Etchison \& Kleist, 2000). Narrative Therapy's focus on qualitative outcomes diverges from the quantitative outcomes that therapy and psychological research typically aims 


\section{International Journal of Social Science and Economic Research}

ISSN: $2455-8834$

Volume: 05, Issue: 07 "July 2020"

to achieve. Therefore, the exclusive dependence on narrative therapy as a psychotherapeutic modality might not yield the most beneficial outcomes for women suffering from anxiety disorders in India, and it must be combined with other forms of cognitive and behavioral therapeutic methods to achieve desired outcomes.

Gender has been found to be one of the most important determinants of mental illness and mental health (W.H.O, 1997). It also impacts access to mental healthcare and therapy in India. Mental healthcare in the country is in its nascent stage, and there is a general lack of awareness around mental health and psychological issues. Healthcare has been restricted to physiological diseases historically. Even though there has been a surge in the number of private and public mental healthcare providers, in the form of therapy and psychiatry centers the quality and reach of these institutions have been inadequate. Moreover, therapeutic solutions to mental health problems continue to be ignored by public authorities and people alike. Clinical psychologists and therapists are limited to the most developed cities, and hence are inaccessible to rural and semiurban populations. Economic barriers further deter healthcare access for many individuals. These problems are far more severe for women- primarily because of the lack of agency at their hands in a patriarchal society. Women who do not have their own disposable income are often denied the agency to make choices by their families, especially when it comes to accessing mental healthcare, an issue that continues to be stigmatized in Indian society. Women with mental illnesses, who are in urgent need of care and therapy are often labeled as hysterical (FII, 2018). Moreover, the lack of presence of women in medicine led women to rely mostly on traditional methods of treatment for ailments which are often unscientific and sometimes have long term adverse effects (Gantara \& Hirve, 1994).

Clinical bias' also presents a problem to the small proportion of women in India who can afford and access mental healthcare. Research suggests that the perceptions, attitudes, and beliefs of doctors and therapists affect the diagnosis and treatments suggested by them. Therapy, especially narrative therapy, which depends on a conducive and cooperative relationship and engagement between the patient and the therapist is hence deterred by the presence of gender bias. Instead of breaking down negative stereotypes and replacing them with positive co-authored narratives, therapy can result in victim-blaming and reinforcing of traditional narratives that perpetuate discrimination against women in the first place (Kumar, et. al., 2013). Women belonging to oppressed communities in India (Scheduled Castes, Scheduled Tribes, Backward Castes) are the worst victims of malpractices in therapy, because they face layered oppression because of their caste and gender identity, even at the hands of female therapists.

Mental health has been deprioritized by subsequent central governments in health and public policy. Recent research suggests that over 150 million Indians are in need of active mental 


\section{International Journal of Social Science and Economic Research}

ISSN: $2455-8834$

Volume: 05, Issue: 07 "July 2020"

interventions, which presents a challenge for a health system that is inefficient and inequitably distributed (Mahajan, et. al., 2019). Developments and advancements have been made in the private sector, and there has been a steady growth in mental health clinics and therapeutic centers in developed regions. However, they are inaccessible to most Indians because of geographic or economic barriers. Most progress in the field of providing mental health to the neediest stakeholders in society has been made by non-governmental organizations and grassroots level initiatives. Community-based models and interventions have yielded positive results in Maharashtra and Goa (Pathare, et. al., 2017). Organizations like The Banyan (which works in partnership with the Tata Institute of Social Sciences) even provide emergency care and critical time interventions to women (Balan, 2018).

\section{CONCLUSION}

Narrative therapy seeks to break down negative stereotypes that adversely impact the mental health and self-esteem of individuals, only to replace it with empowering narratives based on actual skills and values a patient holds dear. It is implied that narrative therapy is most effective for those affected by demoralizing, and oppressive social narratives. Most communities in India follow strict religious and social codes that combine to create a system of Brahmanical Patriarchy (which is further supported by oppressive doctrines of Abrahamic religions) which is responsible for the exclusion and marginalization of women. This practically manifests itself in inquiry in literacy rates and employment levels between both genders. Higher prevalence of anxiety and depression disorders amongst Indian women as compared to men can also be traced to regressive social narratives. Thus, the scope of implementation of narrative therapy as a treatment intervention for anxiety disorders amongst Indian women, similar to its need- is immense. In order to ensure that the implementation of narrative therapy interventions is not limited to urban and developed regions of the country, there is a need to account for and resolve barriers faced by women of diverse backgrounds (many of whom face intersectional oppression) that prevent their access to mental healthcare.

Narrative therapy has proven to be pathbreaking in treating anxiety disorders, especially amongst marginalized communities across different contexts. There is a need for local governments to work with and supplement grassroots level initiatives, and non-governmental organizations in an attempt to improve the accessibility of women from diverse backgrounds to novel developments in mental healthcare, specifically narrative therapy.

\section{BIBLIOGRAPHY}

Balan, S.S., These Kerala rehabilitation homes help people with mental illness integrate into society. The News Minute. 11th March 2018 


\section{International Journal of Social Science and Economic Research}

ISSN: $2455-8834$

Volume: 05, Issue: 07 "July 2020"

Brown, C., and Augusta-Scott, T. (2007). Narrative Therapy. Sage Publications. Accessed on 11th July 2020

Etchison, M., and Kleist, D.M. (2000). Review of Narrative Therapy: Research and Review, Family Journal. Accessed on 14th July 2020

Feminism in India. Why We Need To Focus On Women's Mental Health. 22nd November 2018

Fish, V. (1993). Post Structuralism in Family Therapy: Interrogating the Narrative/Conversational Mode. Journal of Family Therapy. Accessed on 13th July 2020

Gantara, B., and Hirve, S. (1994). Male Bias in health care utilization for under-fives in a rural community in western India. Bulletin of the World Health Organisation. Accessed on 14th July 2020

Ghavami M., Fatehizadeh M., Faramarzi S., and Nouri E.A. (2014) The effectiveness of the narrative therapy on the social anxiety and the self-esteem among the girl students. Journal of Social Psychology. Accessed on 13th July 2020

Kangaslampi S., Garoff F., and Peltonen K. (2015). Narrative exposure therapy for immigrant children traumatized by war: study protocol for a randomized controlled trial of effectiveness and mechanisms of change. BMC Psychiatry. Accessed on 13th July 2020

Kohli, N. Anxiety and depression more prevalent among women than men in India: Study. The Week. 23rd December 2019

Kumar, P., Nehra, D.K., and Dahiya, S. (2013). Women Empowerment and Mental Health: A Psychosocial Perspective. Delhi Psychiatry Journal. Accessed on 14th July 2020

Looyeh M.Y., Kamali K, Ghasemi A, and Tonawanik P (2014). Treating social phobia in children through group narrative therapy. Journal of Artistic Psychotherapy. Accessed on 11th July 2020

Mahajan, P.B., Rajendran, P.K., Sunderamurthy, B., Keshavan, S. and Bazroy, J. (2019). Analyzing Indian mental health systems: Reflecting, learning, and working towards a better future. Journal of Current Research in Scientific Medicine. Accessed on 14th July 2020

Mehta, A. Rewrite Your Story. Pune Mirror. 27th March 2019

Melchert, T.P. (2011). Understanding and Resolving Theoretical Confusion in Professional Psychology. Foundations of Personal Psychology. Accessed on 10th July 2020 
International Journal of Social Science and Economic Research

ISSN: 2455-8834

Volume: 05, Issue: 07 "July 2020"

Minuchin, S. (1998). Where is the Family in Narrative Family Therapy? Journal of Marital \& Family Therapy. Accessed on 14th July 2020

Norcross J.C. (2007). Prescriptive Eclectic Therapy. American Psychological Association. Accessed on 11th July 2020

Pathare S., Shields-Zeeman L., Walters B.H., Kapadia-Kundu N., and Joag K. (2017). . Promoting wellbeing and improving access to mental health care through community champions in rural India: The Atmiyata intervention approach. International Journal of Mental Health Systems. Accessed on 14th July 2020

Ravan, A., and Esfandeyari, M. (2016). The Role of Narrative Therapy in Reducing Social

Anxiety and Improve Social Interactions. International Journal of Philosophy and SocialPsychological Sciences. Accessed on 13th July 2020

Sagar, R., Dandona, R., et. al. (2017). The burden of mental disorders across the states of India: the Global Burden of Disease Study 1990-2017. The Lancet Psychiatry. Accessed on 10th July 2020

White, M. (2007). Maps of Narrative Practice. Accessed on 13th July 2020

White, M. and Epston, D. (1990). Narrative means to therapeutic ends. W. W. Norton. Accessed on 11th July 2020

Winslade, J. and Monk, G. (2000) Narrative Mediation: A New Approach to Conflict Resolution. Jossey-Bass. Accessed on 10th July 2020

World Health Organization (1997). World Health Organization. Nations for Mental Health: A Focus on Women. Accessed on 14th July 2020 